\title{
Ofelia García and Colin Baker (eds): Bilingual Education: An Introductory Reader
}

\author{
Multilingual Matters Limited, Clevedon, UK, 2007, vii + 301 pp, \\ $\mathrm{Pb} € 21.95$, ISBN 9781853599071
}

\author{
Ariana Mangual Figueroa
}

Received: 30 March 2008/Accepted: 12 December 2008/Published online: 6 January 2009

(C) The Author(s) 2009. This article is published with open access at Springerlink.com

Bilingual Education An Introductory Reader (BEIR) is a resource for "instructors, researchers and students" studying the "fundamental and formative ideas on Bilingualism and Bilingual Education" (p. vii). As the editors' introduction makes clear, the volume is more pedagogic than academic, seeking to scaffold the learning experiences of new teachers. Researchers, however, will find that the bibliographies are a valuable reference. BEIR has three goals: gathering the field's major works into a single volume, exposing readers to key concepts about bilingual teaching and learning, and providing an extensive bibliography for further study. Two emphases distinguish this text from similar readers: first, its focus on interactivity, how it aims "to stimulate a process of introspection, generalization and personalization" (p. vii). Towards this end, each article is followed by a series of questions and activities that encourage readers to explore the language practices of their communities. Second, unlike technical texts that bracket political questions to focus on cognitive processes, the editors have selected essays that emphasize the need to place language teaching in its social and political context.

Part one, "Varieties of Bilingual Education," outlines classic bilingual instructional models. Freeman describes the features of common language education programs and aligns them with standards developed by Teachers of English to Speakers of Other Languages (TESOL) and the Center for Applied Linguistics (CAL), among others. The international and indigenous histories described by Johnstone and McCarty reveal why diverse communities have chosen to develop immersion programs. Torres-Guzmán reviews research conducted in the U.S. that clarifies the key characteristics of dual language programming and debunks widespread myths about this model, including the misconception that dual language programs segregate students. The framework developed by Villarreal helps principals and teachers identify the strengths and challenges of transitional bilingual

\footnotetext{
A. Mangual Figueroa $(\bowtie)$

University of California, Berkeley, Berkeley, CA, USA

e-mail: amangual@berkeley.edu
} 
education programs in order to implement reforms that improve students' learning. The reader emerges from part one with a nuanced understanding of three bilingual models: immersion, dual language and transitional bilingual.

Part two, "History, Policy, and Politics of Bilingual Education," places the preceding overview in its broader sociopolitical context. The authors outline educational "mechanisms" or "policy devices" to show how macro-political processes impact routine classroom practices (Shohamy 2006, p. 54). Part two is a rallying cry for educators and students of education to support bilingual programming in various ways, from voting in statewide referenda to designing curricula. Wiley provides an historical overview of U.S. language policy to show how and why language rights have been granted and repealed for different groups over time. Using Proposition 227 (an anti-bilingual education mandate passed in California) as an example, Cummins traces the impact of social policy on students' learning. He illustrates how English-only campaigns exploit xenophobic, antiSpanish ideology, leading to anti-bilingual education legislation and lower student achievement. By framing bilingual education as a "linguistic human right" (p. 137), Skutnabb-Kangas counters popular misconceptions regarding language instruction, including the belief that students learn English best when taught exclusively in English. Crawford summarizes the debate surrounding bilingual education in the U.S. by presenting viewpoints from both advocates and critics, while calling for advocates to strategize politically to counter the spreading English-only movement. By the end of part two, readers have considered the complex relationship between politics and pedagogy, and contemplated language education policy as a site for contesting linguistic and social inequality.

Part three, "Languages and Literacies in Bilingual Education," moves from a consideration of language policy to the bilingual classroom itself. As Johnstone shows, dual immersion teachers use research-based criteria to select appropriate didactic materials and provide quality literacy instruction. Hornberger explores three central metaphors in the field of language education-language ecology, continua of biliteracy, and implementational space-and provides qualitative data from South Africa and Bolivia to illustrate their importance. "The Curriculum Cycle" presented by Gibbons can be used by teachers to plan literacy activities that enhance students' oral and written fluency. The Vygotskian concepts that Walqui uses link sociocultural learning theory and classroom pedagogy. Kelly, Gregory and Williams share research showing that Bangladeshi children in the U.K. engage in distinct yet complementary literacy practices at home and school. They urge teachers to find the overlap in these practices to help foster students' language acquisition.

Part four, "Issues in Teaching, Learning, and Assessment in Bilingual Education," tracks the challenges and successes of various instructional strategies. Feuerveger describes how a bilingual school in Israel cultivates language learning and awareness between Arab and Israeli students and families. The classroom transcripts that Dong presents exemplify how teachers scaffold both language acquisition and science content learning in English as a Second Language classes. Moll's classic essay uses a sociocultural approach to debunk the idea that language minority students are academically or culturally deficient. Ortiz briefly outlines the 
supportive relationships that must be nurtured between administrators, teachers and parents in order to foster the language development of English Language Learners with special needs. As he demystifies the complex accountability policies of No Child Left Behind, Abedi identifies the challenges in creating fair and consistent criteria for assessing English Language Learners. Part four provides a compelling cross-section of bilingual practices in international classrooms and diverse methodologies for measuring their effects.

$B E I R$ achieves its goal of actively engaging its readers and teaching them several vocabularies-political, empirical, and pedagogical—that will strengthen their ability to advocate for bilingual education. The questions and activities following each chapter guide readers on the threefold process defined in the introduction. In an edited volume of reprinted chapters, there is always a tension between the canonical and contemporary, and while this reader compiles many important essays, it would have benefited from more articles addressing the specific challenges of the No Child Left Behind era. While references to current publications can be found in the "Further Reading" sections, greater attention to recent policy changes would enable teachers to interrogate their role in resisting and revising contemporary language policy. Regardless, this text is an important contribution to the construction of effective and equitable bilingual education programs.

Open Access This article is distributed under the terms of the Creative Commons Attribution Noncommercial License which permits any noncommercial use, distribution, and reproduction in any medium, provided the original author(s) and source are credited.

\section{Reference}

Shohamy, E. (2006). Language policy: Hidden agendas and new approaches. New York: Routledge.

\section{Author Biography}

Ariana Mangual Figueroa is a Doctoral Candidate at the University of California, Berkeley. Her scholarly interests include language socialization and policy, with a focus on the relationship between language use and immigrant identities in the United States. 